\title{
Normal Value of Antistreptolysin O Titer in Rheumatoid Heart Disease who Are on Secondary Prophylaxis and in Apparently Healthy Children at Debre Berhan Referral Hospital, Ethiopia
}

\author{
Tsegahun Asfaw*, Demissew Shenkute, Mihret Tilahun, Tizazu Zenebe, Nigus Zegeye \\ Department of Medical Laboratory Science Unit, College Medicine, Debre Berhan University, Debre Berhan, \\ Ethiopia
}

*Corresponding Author: Tsegahun Asfaw, Department of Medical Laboratory Science Unit, College Medicine, Debre Berhan University, Debre Berhan, Ethiopia, Email: tsegahun.asfaw12@gmail.com

\begin{abstract}
Anti-streptolysin $O$ (ASO) titer assists for the diagnosis of streptococcal infections and their sequele. Normal value of Anti-streptolysin $O$ titer is not available for Ethiopian populations. This study establish and compare the normal reference value in Rheumatoid Heart Disease (RHD) and in apparently healthy children. A cross sectional study methods was employed to collect blood samples from RHD patients who are on secondary prophylaxis, and apparently healthy children at pediatric clinic of Debre Brehan referral hospital. The blood sample was collected for ASO titer determination. And finally, the data will be analyzed using SPSS version 21 and P-value less than or equal to 0.05 was taken as statistically significant. A total of 123 children on secondary prophylaxis for RHD in the age range of 5-15 years are included in these study. Of these, 65 (52.8) were male and 58 (47.2\%) were female. The ASO ULN for the total subjects was $800 \mathrm{IU} / \mathrm{ml}$. The ASO ULN for both male and female children in all age groups was also $800 \mathrm{IU} / \mathrm{ml}$. And also 127 apparently healthy children with the age of 5-15 years were selected and investigated for the ASO ULN. The ASO ULN for the total subjects was $360 \mathrm{IU} / \mathrm{ml}$. The ASO ULN for both male and female children was 320 $\mathrm{IU} / \mathrm{ml}$. The highest ASO ULN was observed for the age group of 9-12 years $400 \mathrm{IU} / \mathrm{ml}$. These study suggest, most children with RHD have recent streptococcal infection as evident by raised ASO titer. This study also showed that ASO ULN for apparently healthy children is almost similar to those reported in countries with different climates.
\end{abstract}

Keywords: Rheumatic heart disease, apparently healthy, ASO titers, normal value

\section{INTRODUCTION}

Rheumatic heart disease (RHD) remains a leading cause of morbidity and mortality among young adults in the developing world, accounting for at least 345,000 deaths annually $[1,2]$. RHD is the long term consequence of rheumatic fever, an autoimmune response to Group A streptococcal pharyngitis [3]. Without prophylaxis, patients with RHD are at risk of recurrent attacks of rheumatic fever resulting in ongoing inflammation and fibrosis with consequent valvular damage $[4,5]$. Although its incidence is decreasing in industrialized countries, RHD remains a major challenge in the rest of the world. The highest prevalence is in sub-Saharan Africa with a rate of 5.7 per 1000, compared to 1.8 per 1000 in North Africa, and 0.3 per 1000 in economically advanced countries [6]. In Ethiopia, RHD is the number one cardiac problem in children with a

ARC Journal of Cardiology prevalence rate of 4.6-7.1 per 1000 [7, 8]. Particularly frustrating has been the fact that RHD are theoretically preventable but still remains a problem in developing countries. Reason most advanced is that these countries cannot afford the economic and social cost involved [9].

Rheumatic Heart Disease (RHD) are an autoimmune disease that follows infection with GAS; however, the isolation of GAS is uncommon $(<15 \%)$, and so confirmation of the diagnosis often relies on streptococcal antibody tests [10]; the most frequently performed tests are anti-streptolysin O (ASO) titer [11]. If possible, it is recommended that the titer be determined in the acute phase and then determined in the convalescent phase 14 to 28 days later, with a positive result defined as a rise in titer of twofold or more [12]. However, it is not always practicable to obtain a second sample 
Normal Value of Antistreptolysin O Titer in Rheumatoid Heart Disease who Are on Secondary Prophylaxis and in Apparently Healthy Children at Debre Berhan Referral Hospital, Ethiopia

for titer determination, particularly in developing countries, where acute rheumatic heart disease is the most common. Therefore, it is generally accepted that if only a single specimen is available, a titer greater than the upper limit of normal at the initial testing can be considered presumptive evidence of a preceding streptococcal infection [12, 13, 14]. However, because of the differences in ASO titers with age, it is recommended that age-stratified upperlimit-of-normal values should be determined for populations of interest by testing people who have not had a recent streptococcal infection. Yet, there has been no investigation of upperlimit-of-normal values for populations in Ethiopia. Thus conclusions drawn may be misleading. Therefore, this study aims to establish and compare normal range of ASO titers in rheumatic heart disease patients who are on secondary prophylaxis and in apparently healthy children among different age groups.

\section{Materials ANd Methods}

\subsection{Study Area and Periods}

The study was conducted at pediatric clinic of Debre Berhan referral hospital from November, 2016 - September, 2017.

\subsection{Study Design}

Cross sectional study design was employed.

\subsection{Study Participants and Sample Size}

Convenient sampling technique was used to select 250 children with the age of 5-15 years fulfilling the inclusion criteria and attending pediatric clinic of Debre Berhan referral hospital. Among these 123 were confirmed RHD patients who are on secondary prophylaxis, and 127 were apparently healthy children who are devoid of streptococcal infections.

\subsection{Sample Collection, Handling, Transport and Analysis}

A total of $3 \mathrm{ml}$ of venous blood was collected using sterile $5 \mathrm{ml}$ syringes and immediately transferred to a glass tube without anticoagulant. It was transported to Debre Berhan university medical microbiology laboratory and then serum was used for ASO titer determination. The demographic data was collected using a questionnaire. Clinical information was obtained from all patients by reviewing medical records.

\subsection{Data Quality Control Measures}

Standard Operational Procedures were strictly followed during the whole laboratory procedures.

\subsection{Data Entry, Management and Analysis}

Data obtained from each samples was analyzed using SPSS version 21 software. A p-value of less than or equal to 0.05 was considered as statistically significant difference. The mean, standard deviation, and median for ASO serum levels among the tested subjects were calculated. The median and cut of 80 percentile were used for normal ASO titer determination.

\subsection{Ethical Considerations}

Ethical approval was obtained by Debre Berhan university research and review committee and official permission was obtained from head department of Debre Berhan referral hospital. Written informed consent was obtained from each child's parent or guardian and assent from study participants older than 12 years.

\section{Results}

A total of 123 children on secondary prophylaxis for RHD in the age range of 5-15 years are included in these study. Of these, 65 (52.8) were male and $58(47.2 \%)$ were female; $69(56.1 \%)$ were from rural and $54(43.9 \%)$ were from urban area. The children were symmetrically distributed in age groups and majority of the participant were in the age group of 9-12 years. This study shows the ASO ULN for the total subjects was $800 \mathrm{IU} / \mathrm{ml}$ with a median 400 $\mathrm{IU} / \mathrm{ml}$. The ASO ULN for both male and female children were $800 \mathrm{IU} / \mathrm{ml}$ with a median of $400 \mathrm{IU} / \mathrm{ml}$. The ASO ULN was $800 \mathrm{IU} / \mathrm{ml}$ with a median of $400 \mathrm{IU} / \mathrm{ml}$ for all age groups (Table 1).

For ASO normal values levels a total of 127 children with the age of 5-15 years, 68 (53.5\%) male and $59(46.5 \%)$ female were conveniently selected and investigated ASO ULN. The children were symmetrically distributed in age groups, $42(33.1 \%)$ were in age group of 5-8 years, $43(33.8 \%)$ were in age group of 9-12 years and $42(33.1 \%)$ were in age group of 1315 years. The ASO ULN for the total subjects was $360 \mathrm{IU} / \mathrm{ml}$ with a median $200 \mathrm{IU} / \mathrm{ml}$. The ASO ULN for both male and female children were $320 \mathrm{IU} / \mathrm{ml}$ with a median of $200 \mathrm{IU} / \mathrm{ml}$. The highest ASO ULN was observed for the age group of 9-12 years $(400 \mathrm{IU} / \mathrm{ml}$ with median of 200IU/ml) (Table 2). 
Normal Value of Antistreptolysin O Titer in Rheumatoid Heart Disease who Are on Secondary Prophylaxis and in Apparently Healthy Children at Debre Berhan Referral Hospital, Ethiopia

Table1. The cut of 80 percentile upper-limit of normal reference values for ASO titer by sex and age groups for children $5-15$ years

\begin{tabular}{|c|c|c|c|c|}
\hline \multirow[b]{2}{*}{ Characteristics } & \multirow[b]{2}{*}{ No (\%) of subjects } & \multicolumn{3}{|c|}{ ASO (IU/ml) } \\
\hline & & Mean \pm SD & Median & $80 \%$ upper limit of normal \\
\hline \multicolumn{5}{|l|}{ Sex } \\
\hline Male & $65(52.8)$ & $492.3 \pm 329.9$ & 400 & 800 \\
\hline Female & $58(47.2)$ & $500 \pm 337.7$ & 400 & 800 \\
\hline \multicolumn{5}{|l|}{ Age } \\
\hline $5-8$ & $40(32.5)$ & $470 \pm 305.7$ & 400 & 800 \\
\hline $9-12$ & $52(42.3)$ & $447.1 \pm 290.1$ & 400 & 800 \\
\hline $13-15$ & $31(25.2)$ & $606.3 \pm 404.7$ & 600 & 800 \\
\hline Total & $123(100)$ & $495.9 \pm 332.2$ & 400 & 800 \\
\hline
\end{tabular}

Table2. The cut of 80 percentile upper-limit of normal reference values for ASO titer by sex and age groups for children 5-15 years

\begin{tabular}{|c|c|c|c|c|}
\hline \multirow[b]{2}{*}{ Characteristics } & \multirow[b]{2}{*}{ No. $(\%)$ of subjects } & \multicolumn{3}{|c|}{ ASO (IU/ml) } \\
\hline & & Mean \pm SD & Median & $80 \%$ upper limit of normal \\
\hline \multicolumn{5}{|l|}{ Sex } \\
\hline Male & $68(53.5)$ & $245.2 \pm 99.5$ & 200 & 320 \\
\hline Female & $49(46.5)$ & $244.4 \pm 96.9$ & 200 & 320 \\
\hline \multicolumn{5}{|l|}{ Age } \\
\hline $5-8$ & $42(33.1)$ & $240 \pm 81.02$ & 200 & 360 \\
\hline $9-12$ & $43(33.8)$ & $266.6 \pm 96.6$ & 200 & 400 \\
\hline $13-15$ & $42(25.2)$ & $240 \pm 82.8$ & 200 & 360 \\
\hline Total & $127(100)$ & $243.6 \pm 91.8$ & 200 & 360 \\
\hline
\end{tabular}

\section{DISCUSSION}

The diagnostic criteria of rheumatoid heart disease is ASO level greater than $200 \mathrm{IU} / \mathrm{ml}$. Anti-streptolyasin $\mathrm{O}$ (ASO) serum titer in excess of $200 \mathrm{IU} / \mathrm{ml}$ is considered abnormally high and suggest either recent infection with streptococci or persistently high antibody level due to earlier exposure in hypersensitive persons [14]. In our study a total of 123 patients of RHD were included. The ASO ULN for the total subjects was $800 \mathrm{IU} / \mathrm{ml}$ with a median 400 IU/ml. The ASO ULN for both male and female children were $800 \mathrm{IU} / \mathrm{ml}$ with a median of $400 \mathrm{IU} / \mathrm{ml}$. The ASO ULN was $800 \mathrm{IU} / \mathrm{ml}$ with a median of $400 \mathrm{IU} / \mathrm{ml}$ for all age groups. Different study were indicated that in chronic RHD patients, ASO ULN was less than standard $(200 \mathrm{IU} / \mathrm{ml})$ due to the effect of penicillin on the immune response to streptococci [15], But in this study ASO ULN was higher $(800 \mathrm{IU} / \mathrm{ml})$ than standard $(200 \mathrm{IU} / \mathrm{ml})$. This might be attributed to the recent streptococcal infection in which $(68(55.3 \%)$ patients had $\leq 3$ months duration of treatment.

The present study also designed to establish normal range of ASO titers in apparently healthy individuals among different age groups. Most of the reports in the literature dealing with "normal" ASO titers have been based on the study of healthy subjects. We chose pediatric patients with no clinical history of a recent streptococcal infection, rather than healthy subjects, for our study because study conducted in America [14] consider that their titers are more relevant as a base line for suggesting what constitutes a significant ASO titer. The reason for this is that the majority of serum specimens submitted to a laboratory for ASO tests will be from patients rather than from healthy subjects, even though the patients may not have a streptococcal infection. In present study the ASO ULN for the total subjects was $360 \mathrm{IU} / \mathrm{ml}$ with a median $200 \mathrm{IU} / \mathrm{ml}$. The ASO ULN for both male and female children were $320 \mathrm{IU} / \mathrm{ml}$ with a median of $200 \mathrm{IU} / \mathrm{ml}$. The highest ASO ULN was observed for the age group of 9-12 years $(400 \mathrm{IU} / \mathrm{ml}$ with median of $200 \mathrm{IU} / \mathrm{ml}$ ) followed by $360 \mathrm{IU} / \mathrm{ml}$ for the age group 5-8 years and age group 13-15 years with a median of $200 \mathrm{IU} / \mathrm{ml}$. The ASO ULN in this study were found to be roughly similar to those reported from other regions. In comparison with data from the Minnesota, USA (333 Todd unit) [14], Mumbai, India (305 IU/ml)[16], Australia (320 $\mathrm{IU} / \mathrm{ml})$ [17] and Korea (326 IU/ml) [18]. Relatively higher ASO ULN was obtained from study conducted in Sana'a, Yemen (276.2 IU/ml)[19], Fiji (276 IU/ml)[20], USA (240 $\mathrm{IU} / \mathrm{ml})$ [21], Tanzania (200 IU/ml)[22], Sweden (200 Todd's unit) [23] and in a different regions of India (239 IU/ml) [24]. However, lower result 
Normal Value of Antistreptolysin O Titer in Rheumatoid Heart Disease who Are on Secondary Prophylaxis and in Apparently Healthy Children at Debre Berhan Referral Hospital, Ethiopia

was obtained from study conducted in Egypt (400IU/ml) [25].

Most of these values exceeded the normal level set by laboratories which is $200 \mathrm{IU} / \mathrm{mL}$. The higher ASO titers in Yemen and Australia, Fiji and India are probably due to the fact that tonsillitis and impetigo are endemic particularly in children [20, 26]. In Ethiopia, RHD is the number one cardiac problem in children with a prevalence rate of 4.6-7.1 per 1000 [7, 8] suggest that there is high prevalence of tonsillitis and pharyngitis.

Different literature showed that simple non parametric method gives the cutoff values similar to those obtained by the parametric method. However, the parametric method for data analysis that was used in this study has some advantages over the non-parametric method. The non-parametric method often produces unlikely irregular patterns in the centiles with age, unless a large sample is used and wide age intervals are specified [20]. The results may be artificially affected by the choice of age groups, especially when titers have a complex pattern of change with age. This study will recommend that Ethiopians clinicians use single upper limit of normal cutoff value for children aged from 5 to 15 years rather than subage groups. This is because there is minor variability in the year by year values that was found in children aged 5 to 15 years. This study was also suggesting that the female cut off value equal to the male cut off value. This issue has not been discussed by other researchers previously.

\section{Conclusions}

These study suggest that in most children with RHD, have recent streptococcal infection as evident by raised ASO ULN. This finding showed that ASO ULN for apparently healthy are much lower than children with RHD but similar to those reported in countries with different climates and populations and will provide useful baseline data for future studies of interventions against GAS disease in Ethiopia. These data could also be applied for the surrounding area in Ethiopia.

\section{AUTHORS' CONTRIBUTIONS}

TA-performed the laboratory activities, TAanalyzed the data and wrote the manuscript. DS, MT, TZ and NZ reviewed the manuscript. TA,
DS, MT, TZ and NZ participated in its design. All authors read and approved the final manuscript.

\section{ACKNOWLEDGMENT}

We would like to thank Debre Berhan University for giving this opportunity and its fund. We also thank staffs and head or director of Debre Berhan referral hospital for their help during data collection process.

\section{REFERENCES}

[1] Lozano MN, Foreman K, Lim S, Shibuya K, Aboyans $\mathrm{V}$, et al. Global and regional mortality from 235 causes of death for 20 age groups in 1990 and 2010: a systematic analysis for the Global Burden of Disease Study 2010. Lancet. 2012; 380 (9859):2095-128.

[2] Roberts KCS, Steer A, Reményi B, Carapetis J. Screening for rheumatic heart disease: current approaches and controversies. Nat Rev Cardiol. 2013; 10 (1):49-58.

[3] Wood H, Feinstein AR, Taranta A, Epstein JA, Simpson R. Rheumatic fever in children and adolescents: a long-term epidemiologic study of subsequent prophylaxis, streptococcal infections, and clinical sequelae: III. Comparative effectiveness of three prophylaxis regiments in preventing streptococcal infection and rheumatic recurrences. Ann Intern Med. 1964; 60:31-46.

[4] Bland E and Jones T. Rheumatic fever and rheumatic heart disease. A twenty-year report on 1,000 patients followed since childhood. Circulation. 1951; 4:836-43.

[5] Tompkins DG, Boxerbaum B and Liebman J. Long-term prognosis of rheumatic fever patients receiving regular intramuscular benzathine penicillin. Circulation.1972:543-51.

[6] Carapetis JR, Steer AC, Mulholland EK, Weber M. The global burden of group A streptococcal diseases. Lancet Infect Dis. 2005; 5:685-94.

[7] Oli K, Porteous J. Prevalence of rheumatic heart disease among school children in Addis Ababa. East Afr Med J. 1999; 76:601-5.

[8] Oli K, Tekle-Haimanot R, Forsgren L, Ekstedt J. Rheumatic heart disease prevalence among schoolchildren of an Ethiopian rural town. Cardiology. 1992; 80 (2):152-5.

[9] Mandor BI, Asuquo AE, Abia-Bassey L, Benjamin TP, Akpan IA;Etuk IS, et al.Meremiku MM. Antistreptolysin O (ASO) titers and beta-haemolytic streptococcus (BHS) in Children in Calabar, Nigeria. IOSR Journal of Nursing and Health Science. 2013; 1(5): 4246. 
Normal Value of Antistreptolysin O Titer in Rheumatoid Heart Disease who Are on Secondary Prophylaxis and in Apparently Healthy Children at Debre Berhan Referral Hospital, Ethiopia

[10] Martin DR., Voss LM, Walker SJ and Lennon D. Acute rheumatic fever in Auckland, New Zealand: spectrum of associated group A streptococci different from expected. Pediatr. Infect. Dis. J. 1994; 13:264-269.

[11] Shet A and Kaplan EL.Clinical use and interpretation of group A streptococcal antibody tests: a practical approach for the pediatrician or primary care physician. Pediatr. Infect. Dis. J. 2002; 21:420-426.

[12] Wannamaker LW and Ayoub EM. Antibody titers in acute rheumatic fever. Circulation 1960; 21:598-614.

[13] Kaplan EL, Top FH, Dudding BA, and Wannamaker LW. Diagnosis of streptococcal pharyngitis: differentiation of active infection from the carrier state in the symptomatic child. J. Infect. Dis. 1971; 123:490-501.

[14] Klein GC, Baker CN, and Jones WL. "Upper limits of normal" antistreptolysin $\mathrm{O}$ and antideoxyribonuclease B titers. Appl. Microbiol. 1971, 21: 999-1001.

[15] Gerber MA, Baltimore RS, Eaton CB, et al. (2009). Prevention of rheumatic fever and diagnosis and treatment of acute Streptococcal pharyngitis: a scientific statement from the American Heart Association Rheumatic Fever, Endocarditis, and Kawasaki Disease Committee of the Council on Cardiovascular Disease in the Young, the Interdisciplinary Council on Functional Genomics and Translational Biology, and the Interdisciplinary Council on Quality of Care and Outcomes Research: endorsed by the American Academy of Pediatrics. Circulation, 119:1541-51.

[16] Karmarkar MG, Venugopal V, Joshi L, and Kamboj R. Evaluation \& revaluation of upper limits of normal values of anti-streptolysin $\mathrm{O}$ and ant-deoxyribonuclease B in Mumbai. Indian J. Med. Res. 2004; 119 (Suppl.):26-28

[17] Danchin, MH, Carlin JB, Devenish W, Nolan TM, and Carapetis JR. New normal ranges of antistreptolysin $\mathrm{O}$ and anti-deoxyribonuclease
B titres for Australian children. J. Paediatr. Child Health. 2004; 41:583-586.

[18] Kim S. and Lee YN. Asymptomatic infection by Streptococcus pyogenes in school children and diagnostic usefulness of antideoxyribonuclease B. $J$ Korean Med Sci.2005; 20:938-40.

[19] Khaled AA and Hassan AA.Anti Streptolysin O; Normal Values for Healthy Children Aged from 5 to 15 Years Old in Sana'a City-Yemen. Annals of Clinical and Laboratory Research.2015; Vol. 3 No. 1:1

[20] Steer AC, Vidmar S, Ritika R, Kado J, Batzloff $\mathrm{M}$, et al. Normal Ranges of Streptococcal Antibody Titers Are Similar Whether Streptococci Are Endemic to the Setting or Not. Clin Vaccine Immunol.2009; 16: 172-175.

[21] Kaplan EL, Rothermel CD, and Johnson DR.Antistreptolysin $\mathrm{O}$ and antideoxyribonuclease B titers: normal values for children ages 2 to 12 in the United States. Pediatrics. 1998; 101:86-88.

[22] Mhalu FS and Matre R. Antistreptolysin O and antideoxyribonuclease B titres in blood donors and in patients with features of nonsuppurative sequelae of group A streptococcus infection in Tanzania. E Afr Med J. 1995; 72:33-6.

[23] Nimmo GR, Tinniswood RD, Nuttall N, Baker GM, and McDonald B. Group A streptococcal infection in an aboriginal community. Med. J. Aust.1992; 157:521-522.

[24] Sethi S, Kaushik K, Mohandas K, Sengupta C, Singh S, and Sharma M. Anti-streptinolysin O titres in normal healthy children aged 515.Indian Pediatr. 2003: 40:1068-1071.

[25] Alyaa Amal Kotby, NevinMamdouhHabeeb and Sahar Ezz El ElarabAntistreptolysin O titer in health and disease: levels and significance. Pediatric Reports 2012; 4:e8.

[26] Yemen MHP. Newsletter- supply 13. Medical Statistical Department, Ministry of Health and Population, ROY. 2013.

Citation: Tsegahun Asfaw, Demissew Shenkute, Mihret Tilahun, Tizazu Zenebe, Nigus Zegeye. Normal Value of Antistreptolysin O Titer in Rheumatoid Heart Disease who Are on Secondary Prophylaxis and in Apparently Healthy Children at Debre Berhan Referral Hospital, Ethiopia. ARC Journal of Cardiology. 2019; 5(1): 6-10. doi:dx.doi.org/ 10.20431/2455-5991.0501002.

Copyright: (c) 2019 Authors. This is an open-access article distributed under the terms of the Creative Commons Attribution License, which permits unrestricted use, distribution, and reproduction in any medium, provided the original author and source are credited. 